Juan Manuel Bergallo*, María Rebeca Medina**, Silvia Costanzo***, Mara Carmignani**** , Cecilia Tortone $^{* * * *}$, Claudia Rosa ${ }^{* * * * * *}$

\title{
El proceso proyectual en la vivienda latinoamericana, siglos $\mathrm{XX}-\mathrm{XXI^{1 }}$
}

The project process in latin american housing in the $20^{\text {th }}$ and $21^{\text {st }}$ centuries.

\section{Cómo citar:}

Bergallo, J., Medina, M., Costanzo, S., Carmignani M., Tortone C., \& Rosa. C. (2018). El proceso proyectual en la vivienda latinoamericana, siglos XX-XXI. Designia, 6 (1), 53-77

${ }^{1}$ Este artículo forma parte del proyecto investigativo Observatorio virtual de Arquitectura contemporánea de Córdoba, 1990-2014, cuyo director es el arquitecto Juan Manuel Bergallo y su codirectora la arquitecta Rebeca Medina. Es subsidiado mediante SECyT UNC 2014-15 y cuenta con la resolución rectoral 1565/14.

*Bergallo, Juan Manuel. Arquitecto. FAUDI, UNC. Prof.

Titular de Historia de la Arquitectura Latinoamericana en la FAUD-UNC. Ex Director de Patrimonio Cultural de

la Prov. de Cba. y ex Director del Museo de la Manzana Jesuítica,Patrimonio Mundial. Miembro de la Junta Pcial. de Historia de Córdoba y de la Comisión Asesora de Patrimonio municipal. Autor de dos libros y múltiples capítulos y artículos sobre temas de su especialidad. Es Director de proyectos de investigación sobre Arquitectura Cordobesa del siglo XX y Curador de Muestras sobre dicha producción. E-mail: juanmanuelbergallo@yahoo.com.ar ORCID: 0000-0002-7605-6815

**Medina, María Rebeca. Arquitecta FAUDI, UNC. Master Internacional Rehabilitación del Patrimonio Edificado. CICOP, España. Master Gestión del Patrimonio y Desarrollo

Territorial, Universidad Mayor de San Simón, Bolivia. Docente Investigador Prof. Adjunto, Cátedra de Historia de la Arquitectura IA y IIIA, FAUD-UNC. Directora del Museo

Virtual de Arquitectura, UNC

Miembro CICOP España y Argentina; ICOMOS Argentina, Consultora UNESCO-ICOMOS Asesora Honoraria Comisión Nacional de Museos, Monumentos y Lugares Históricos. E-mail: omrebecamedina@gmail.com ORCID: 0000-0003-2094-5143

\section{Palabras clave:}

Diseño, identidad, casa unifamiliar, región.

Key words:

Design, identity, single family house, region.

Recibido: 18/10/2017

Aceptado: 10/09/2018 
${ }^{* * * C}$ Costanzo, Silvia Beatriz. Arquitecta, FAUDI, UNC. 'Specialista in Restauro dei Monumenti’ Universitá La Sapienza, Roma Italia. Prof. Asistente Cátedras Introducción a la Historia de la Arquitectura y el Urbanismo B, Historia de la Arquitectura I B, Historia de la Arquitectura III A (Latinoamericana y Argentina) FAUDI, UNC. Docente Investigadora SECYT UNC. Miembro ICOMOS Argentina. E-mail: arq.silviacostanzo@gmail.com ORCID: 0000-0002-2252-1224

***Carmignani, Mara Gabriela .Arquitecta FAUDI, UNC, 2007.Magíster
“Conservación y Rehabilitación del Patrimonio Arquitectónico", FAUDI,
UNC 2016. Docente Investigador Categoría 5, FAUDI y Profesor asistente
Cátedra de "Historia de la Arquitectura y el Urbanismo Latinoamerica-
nos III A, UNC. Prof. Asistente, Cátedras de "Historia del Arte B" y
"Arquitectura y Urbanismo", Facultad de Derecho. UNLZ.
E-mail: maritacarmignani@gmail.com
ORCID: 0000-0002-9658-9926

*****Tortone, Cecilia. Arquitecta, FAUDI, UNC, 2010. Master DI II livello Restauro Architettonico e Recupero della Belleza dei Centri Storici, Roma Tre, Italia, 2012. Prof adjunta Facultad de Arquitectura, Universidad de Mendoza, sede Rio Cuarto, Cordoba, argentina. Miembro adherente CICOP Argentina. E-mail: c_tortone@hotmail.com ORCID: /0000-0002-4833-0557

******Rosa, Claudia Beatriz. Arquitecta FAUDI, Universidad Nacional de Córdoba, 1990. Postgrado en Desarrollo de Emprendimientos Inmobiliarios,

Escuela de Economía y Negocios Universidad de Belgrano, Buenos Aires. Primer Módulo de la Maestría en Desarrollo Urbano y Regional, Secretaria de Investigación y Postgrado FAUDI, UNC. Doctorando en Doctorado de Arquitectura, DOCTA, FAUDI, UNC. Docente investigador FAUDI, Cátedra de Historia de la Arquitectura y el Urbanismo Latinoamericanos III A, FAUDI, UNC. E-mail: claurosa1111@gmail.com ORCID: 0000-0002-4782-5064

Resumen:

El presente artículo de reflexión indaga en diversos procesos de diseño de la vivienda unifamiliar latinoamericana de los siglos XX y XXI. Dicha tipología, una de las más constantes a lo largo de la historia, se ha mantenido casi inmutable en lo esencial, es decir, en espacios para reunir a la familia, servicios a diferentes escalas y ámbitos para descansar. Lo variable, enfocado en el lenguaje y su significado, ha evidenciado la participación del propietario en el juego de poder de cada momento por medio de tipos que manifiestan el espíritu de la época y el del lugar al introducir innovaciones. En la medida que la vivienda ayuda a construir, delinear 
y manifestar la identidad de cada región y el carácter mestizo de nuestra cultura, a través de ella se reflejan tensiones entre lo local y lo global, el presente y el futuro, y se ponderan conceptos propios del paisaje donde se inserta. Entre tendencias centrípetas y centrífugas, entre lo auténtico y lo ilimitado, las construcciones se acercan a la hibridez conceptual y formal característica del diseño latinoamericano, definido desde sus orígenes por la riqueza contenida en sus multiformes fisonomías.

\section{Abstract:}

This reflection article explores diverse design processes related to the Latin American single-family housing during the 20th and 21st centuries. Such a typology is one of the most constant throughout history, maintaining almost unchanged its essentials, namely, spaces where family gather together, services at different scales and resting areas. In contrast, its language and meaning has varied through types that express the spirit of the times and the spirit of place, evidencing how owners and each epoch's power game are determinant factors for innovations. Housing helps to build and shape every region's identity, manifesting also our culture's mestizo nature and concepts of the landscape it occurs in. It thus reflects tensions between what is local and global, present and future. Amongst centripetal and centrifugal tendencies, flowing from the authentic to the unlimited, the constructions are close to the conceptual and formal hybridity of Latin American design, characterized by the enormous wealth that lies in its multiform physiognomies.

Podría decirse que el término 'doméstico' hace alusión a la condición existencial del hombre frente a la naturaleza, el espacio doméstico se genera a partir de códigos sensibles del habitar humano en la vida cotidiana, y la domesticidad entrelaza un conjunto de emociones asociadas con la intimidad y la consagración del hogar, como también con la sensación de que la casa brinda refugio, recibe y contiene sentimientos.

Rosa Aboy (2005), al reinterpretar a Foucault y apoyarse en Michel de Certau y Pierre Bourdieu, establece que la noción de doméstico no solo se entiende como mecanismo de control, adoctrinamiento y reproducción de la mano de obra necesaria para la producción, sino también como espacio para la práctica de libertades sustraídas del discurso del poder gobernante. Para Rybczynski (2009/1986), la domesticidad 
es inconcebible sin quienes permanecen en la casa. Así, sostiene que el interior de esta no es únicamente un lugar para actividades domésticas, pues las habitaciones y los objetos adquieren vida propia en la imaginación de sus habitantes. En consecuencia, la domesticidad hogareña depende de una rica conciencia de ese interior.

Baldi y Liston (2013), definen lo doméstico como el espacio por excelencia donde lo individual queda delimitado de lo colectivo. Además, invitan a pensar en las transformaciones diarias que convierten los espacios públicos -de movimiento y tránsito- en otros de tipo doméstico, demarcados y apropiados por los individuos. Puede tratarse del ómnibus, una calle o una plaza por donde simplemente se transita. Consciente o inconscientemente se vuelven parte de un acto cotidiano y en ellos se generan, coexisten y colisionan microespacios, pieles no físicas y constituidas por objetos propios que se convierten en extensión de la persona, pero, a la vez, aíslan alguno de sus sentidos, la trasladan a sus universos privados, la distancian de la sociedad y evitan su contacto con los demás, aunque haya cercanía física. En consecuencia, en un mismo espacio de tránsito se reduce la interacción social real.

De la misma forma como el hombre se apropia del espacio público lo hace con el privado y doméstico, aquel donde habita a diario: su casa, habitación, oficina, escritorio o una porción de cada uno de estos se van adaptando por y a la persona. Allí, individuos y grupos disponen objetos y producen ideas, actitudes, situaciones y comportamientos que transforman el sitio, lo identifican y tornan único, reconocible y diferenciable de otros. La apropiación se produce a través de pertenencias visibles, tanto individuales como colectivas. Estos objetos domésticos (mobiliario, utensilios, equipamiento, accesorios) se convierten paulatinamente en protagonistas que configuran la vivienda, rigen sus principios compositivos, reflejan emociones y transmiten la sensación de una casa receptora y contenedora de tales sentimientos.

\section{CASA, VIVIENDA Y HOGAR}

La acción de habitar se enmarca en la de residir en un mismo lugar, en una casa que es uno de los principales atributos del ser, un pasaporte formal y de identidad. La toma de posesión del mundo, la autoafirmación del individuo en su territorio más íntimo se da en la experiencia vital de apropiarse del espacio doméstico, en habitar y habitarse. 
Ballent y Liernur (2014), retoman a Gottfried Semper y afirman que la casa, en su expresión más primaria, amplifica la función protectora del vestido y se emplea en relación con las necesidades y expectativas culturales y espirituales. También rescatan la imagen propuesta por Manuel de Landa, esto es, la casa como un exoesqueleto inventado por los humanos para acumular y conservar energías físicas e intangibles, cuyo carácter es simultáneamente de objeto material y representación social.

Si bien las palabras 'casa' y 'vivienda' son, en general, utilizadas como sinónimos, a lo largo del tiempo han indicado distintos aspectos de los espacios domésticos. 'Casa' es un concepto tradicional y de uso extendido, referido a la relación con un lugar de cobijo, albergue o protección, destinado a funciones de la vida diaria. Por su parte, 'vivienda', término acunado en el siglo XX y de menor aplicación, se asocia con un sentido político y enfatiza en la provisión de tales espacios por parte de poderes estatales o públicos.

La casa remite a una forma de relacionarse con el mundo a través de operaciones humanas que, como acción o como objeto, se denominan habitar. Asimismo, sugiere la idea de lo particular, propio e irrepetible de cada individuo o grupo familiar. La vivienda, en cambio, refiere el espacio doméstico masivo convertido en materia de gobierno, reproducible, con identidad colectiva, en respuesta a propuestas de especialistas y técnicos o a valores de mercado. De este modo, se verifica una tensión entre un sentido antropológico y otro técnico-político que aluden a universos diferentes.

Jorge Taberna (2008) menciona, además, al concepto de hogar. En conexión con la casa, escenario donde ocurren los acontecimientos trascendentes de la vida, pues allí se duerme, se habla, se medita, se sueña, se trabaja, se come y se ama, aparece el hogar, en torno al cual el grupo doméstico da forma al proyecto de su existencia. No solo se trata de cobijo para sobrevivir a las inclemencias del medio ambiente: ambos permiten a cada persona desarrollar un sentido de su propio yo. Los muros delimitadores del entorno más íntimo se convierten en una huella de cada vida, en expresión de la voluntad de permanecer. En este contexto, el hombre puede definirse como "quien habita" y la casa-hogar como uno de las espacios necesarios y exclusivos para la integración de los pensamientos, los recuerdos y los sueños del habitante.

Finalmente, Sylviane Agacinzki (2008) identifica el concepto de 'habitar' en la noción griega de oikos (hogar) y lo entiende como la cohabitación de una pluralidad de existencias. Es el derecho al secreto, a sustraerse a la visibilidad y a definir espacios entre unos y otros como un juego entre lo visible y lo oculto, lo junto y lo separado. 


\section{CASA MICROCOSMOS: EL MUNDO}

Habitar, entonces, no es solo ocupar un espacio, sino existir en el mundo. Sentirse en casa puede sugerir diversos significados, como formar parte de un determinado lugar, experimentar una sensación de protección o un sentimiento de arraigo, todo relacionado con las ideas de identidad y refugio. Es un reencuentro consigo mismo.

Al ser la centralidad algo inherente al ser humano, pues toda persona es desde un lugar y se apropia simbólicamente del centro que en sí misma es para proyectar su relación con el exterior, la casa puede verse como un centro y una manera de sentirse en el mundo. En el caso del niño pequeño, la casa familiar es todo su mundo y habitarla le permite luego habitar el mundo exterior y salir a este.

Estar en casa no es un estado sino, como sostiene Patocka (1988), un movimiento de la existencia que se traduce en un dinamismo vital. Por lo tanto, la falta de casa representa la pérdida de mundo, la destrucción del espacio original de identificación.

Para Bachelard (1986) "la casa es nuestro rincón del mundo, nuestro primer universo" (p. 28) y su experiencia se nos revela como la posibilidad de "tener mundo": un lugar de recogimiento, intimidad, reposo e interioridad; de familiaridad y de proximidad; de regreso y de salida. Desde la visión de Bachelard, "todo espacio realmente habitado lleva como esencia la noción de casa" (p. 28), una imagen vinculada a la tierra propia, a la posibilidad de tener raíces y estabilidad.

La vida empieza bien encerrada, protegida, en el seno de una casa. Es el sujeto quien la llena de recuerdos, alegres o no. Para Bachelard, la imagen primera o arquetípica de la casa es el cosmos: un orden, una continuidad y un referente, un elemento de integración psicológica que se proyecta como mediador entre el mundo del "adentro" y del "afuera". Es el espacio social por excelencia en el cual se conjugan los espacios íntimos, familiares, de carácter social -los otros- y los intermedios -familiar/colectivo-. 
También resulta interesante rescatar la mirada de Levinas (2006), para quien la casa constituye al hombre y, a su vez, está constituida en el hombre mismo. Se produce entonces una identificación entre la persona y su casa, y esta última es condición para tener mundo. En ese juego dinámico del estar se puede regresar a ella, porque casa significa protección, gozo y calidez, en contraste con cuanto se asocia al afuera de o lejos de ella: dificultad, peligro, lucha.

Una vez más se refuerza la idea de la casa concebida como una casa vivida, un espacio habitado que trasciende al geométrico y excede la materialidad del objeto, si bien se expresa a través de esa materialidad. Así, habitar va más allá de la descripción objetiva -de los hechos- y de la subjetiva -de las impresiones- y se transforma en una cargado de sentido que permite la construcción de sí mismo.

\section{CASA CONTENEDOR: ESPACIOS, CUERPOS Y OBJETOS}

\section{Espacios}

El espacio doméstico se configura como el contenedor universal de las emociones y el lugar donde cualquier actividad se convierte en algo íntimo: comer, hablar, trabajar, leer, reproducirse, descansar, mirar TV, escuchar música, limpiar. Pero por ese carácter universal no debe asignársele una concretización formal homogénea, definida y cerrada, pues ponderar la generalidad del concepto de habitar por sobre las distintas formas de vida de los individuos es caer en un concepto errado.

Ya no se puede pensar en estos espacios como algo indiferente, sujeto a la dura geometría y medida. No se trata de abstracciones dadas, sino vivenciadas a cada instante en sus diferentes parcialidades. Se caracterizan por ser próximos, familiares, vitales, al contrario de los uniformes y asépticos propuestos por la ciencia pero que omiten la percepción de los cuerpos entre los cuales vivimos o nos desplazamos.

La casa, por lo tanto, puede analizarse racionalmente por su entidad geométrica, pero el componente humano condensa y defiende la intimidad del espacio que la acontece y la envuelve para convertirse en un lugar sagrado o secreto al ser centro de intimidad. 
El espacio, el cuerpo y los objetos son parte de la vida emocional y la casa es contenedor de las emociones, una extensión de la vida psíquica. En las casas "vividas", todos los rincones son lugares de simbología y tienen su historia (Guerra \& Ravera, 2010). Muchos pensadores han cultivado la metáfora de la casa como imagen del cuerpo, de uno mismo. Cuando un niño dibuja una casa no representa la suya, una donde vivió o que ha sido inventada, sino una estructura contenida en su cabeza, en su memoria corporal interna (Soulé, 1988).

Al respecto, afirma Calmels (2011): “Toda nueva casa, toda nueva posesión habitable, requiere tiempo y conlleva un trabajo del cuerpo en la búsqueda de la apropiación del nuevo espacio" (p. 66).

La casa contiene objetos y es también objeto. Mediante la localización y el modo en que estos son utilizados se conforma la acción de habitar y se codifican los rasgos sociales y culturales a través de los cuales se representa nuestra naturaleza. Así, el uso de una habitación se define por sus objetos, sus muebles y equipamiento.

A partir de la construcción cultural de objetos, el hombre busca un lugar desde el cual reordenar y dominar un territorio según su trayectoria personal y su escala de valores. El objeto termina utilizándose como apropiación de identidades. Los límites del mundo domesticado se organizan con base en nuestras pertenencias, plantea Nietzsche, que solo podemos comprender en un universo conformado por nosotros mismos.

\section{LA IDENTIDAD CULTURAL Y EL TIPO DE VIVIENDA EN LATINOAMÉRICA}

La identidad cultural latinoamericana es dinámica y cambiante, permeable a circunstancias propias y exógenas, en un proceso continuo y multifacético que se construye día a día: "un proyecto a futuro", según palabras de Miguel Rojas Mix.

La vivienda en Latinoamérica evidencia tales características a inicios del siglo XX. Adhiere a la vanguardia propuesta por el movimiento moderno europeo e incorpora la impronta de culturas particulares en ejemplos paradigmáticos de reelaboración y apropiación. Con estas miradas coexisten otras, ancladas en un pasado referente de "lo propio" americano y de los aportes resultantes del mestizaje de elementos indígenas con los modelos coloniales transculturados. Esa búsqueda de la identidad materializada en la vivienda concluye en las décadas finales del siglo con otros objetivos y referentes, en las propuestas de los regionalismos latinoamericanos. 
Ya en el siglo XXI, la inmersión en la "globalización" testimonia la adopción del modelo universal, bien por aspiración o por la dificultad de una escisión del escenario mundial, modelo coexistente con la propuesta de una "vivienda sustentable" como respuesta al agotamiento de los recursos no renovables y al fenómeno del cambio climático global.

\section{LA VIVIENDA EN LA ENSEÑANZA DE LA HISTORIA DE LA ARQUITECTURA}

En la historia está la base de nuestro presente y de nuestro futuro. ¿Cómo podemos saber qué arquitectura y qué vivienda tenemos y queremos hoy si desconocemos las características del territorio donde se desarrolla una ciudad?

Desde la formación universitaria suele proponerse un acercamiento a los elementos y las características particulares de una región, como también a la búsqueda de soluciones de las problemáticas pertinentes al lugar para conocer así el futuro soporte de la actuación profesional. Entender el contexto histórico, la ciudad y la arquitectura permite reflexionar acerca de los modos de habitar y de las modificaciones y transformaciones que la vivienda ha atravesado a lo largo del tiempo.

El diseño que solo crea libremente, carente de una base de conocimientos, está siempre experimentando sin conocer siquiera el presente de una tipología. A esto se suman la complejidad y diversidad de modos de habitar en Latinoamérica.

De acuerdo con Luis Romero (1997), la aproximación al conocimiento de los cambios de la vivienda y sus distintas expresiones territoriales puede aportar claves para ulteriores análisis en las dimensiones sociales y culturales, pues el espacio doméstico constituye uno de los registros privilegiados de las huellas de las acciones y comportamientos de los individuos. Quizás debiera ser un proceso en que desde la Arquitectura se interrogara a la Historia, y no que esta tratara de introducirse a manera de invitado en aquella, como si una fuera ciencia y la otra profesión (Collado, 2008). Se entiende que no hay una sola Historia de la Arquitectura. 


\section{LA VIVIENDA LATINOAMERICANA DEL SIGLO XX AL SIGLO XXI}

La casa, dice Josep Montaner (2011), crea mundos que a veces se abren hacia el paisaje. Allí, el hombre latinoamericano acumula objetos, tales como obras de arte, artesanías, plantas, árboles, libros. Puede ser un resabio de las prácticas del antiguo colonizador, del viajero descubridor y quizás de la nostalgia y necesidad del náufrago.

En la expresión arquitectónica de la vivienda, Montaner reconoce la unifamiliar singular, con "autores" destacados, pertenecientes a un mundo de arquitectura culta. Por otro lado, identifica ejemplos de vivienda social unifamiliar agrupada, opción masiva y popular en la búsqueda de una respuesta digna a la necesidad de habitar.

La vivienda es un tipo constante a lo largo de la historia. Como concepto instrumental de análisis, el tipo es lo representativo, lo esencial de una institución, no es un modelo ni una forma. Pueden existir diferentes tipos según el elemento componente de arquitectura que sea seleccionado para los fines de un análisis (Trecco, 1979).

Al mantenerse casi constante lo esencial del tipo vivienda, es decir, los espacios para reunir a la familia, otras zonas para descansar y servicios a distintas escalas, lo variable se enfoca en el lenguaje y su significado -que incluye la tecnología como expresión- para evidenciar la participación del propietario en el juego de poder de cada época.

\section{Primeras décadas del siglo XX}

En la teoría del Movimiento Moderno (MoMo) europeo, la vivienda es una "máquina para ser habitada", según la definición de Le Corbusier. Esta concepción responde a la función y a los cincos puntos formulados por el maestro en búsqueda de asegurar la fluidez del espacio. Al ser transculturados a Latinoamérica, el diseño abarcó amplias respuestas, desde las materializaciones textuales de la teoría hasta diversos mestizajes de esos cinco principios con realidades materiales y sociales de la región. En este proceso, el significado del objeto resultó predominante. 
Al rechazar los postulados del MoMo, la llamada posmodernidad privilegió, según Richard Weston (2002), aspectos como comunicación y estilo. La casa, sostiene el mismo autor, se ofrece bajo el carácter de un comentario sobre el mundo en lugar de ser parte de él; es un magnífico lugar intemporal para vivir, representativo de los valores de una era dominada por los medios de comunicación. Se identifica así la casa icónica, independiente y simbólica, de grandes superficies, ubicada en barrios cerrados suburbanos, consumida por las publicaciones y el mercado antes que usada por el hombre; y la casa en la ciudad, menos preferida en el mercado al ubicarse en lotes estrechos cuyas restricciones urbanas obligan a ordenamientos de tipos lineales, sin gran desarrollo de fachada e iluminación preferentemente cenital, que retoma la tradición barrial de unir vivienda y trabajo. En los territorios latinoamericanos, las casas icónicas también surgen de la mano de autores destacados, transculturando programas de usos y materiales a los nuevos conjuntos cerrados. Un precedente de este tipo en Argentina se identifica en el chalet, construido masivamente durante el gobierno peronista como materialización del sueño de casa propia. Por su parte, la vivienda en lotes urbanos estrechos continúa siendo objeto de diseño tradicional, aunque no inciden en ella las condicionantes de las restricciones urbanas impuestas a los tejidos de valor patrimonial que suelen citarse para Europa y Estados Unidos.

\section{Siglo XXI}

La posmodernidad crea tantas tendencias como proyectos y autores, quienes pueden acceder a la difusión masiva y digital de sus propuestas. Estas multitendencias, en el marco de la globalización, desafían las nociones convencionales sobre la vivienda, improvisan morfologías, distorsionan escalas, desintegran la forma en múltiples fragmentos individuales con la intención de formar un todo. Además de la continuidad de la casa icónica, Weston (2002) propone categorías como la casa práctica que retoma las relaciones entre región, medio ambiente, cliente, materiales, innovación tecnológica, escala y tradición, para llegar a una variedad en las respuestas de diseño; y la casa del futuro, cuyos referentes orientales tienen poca trascendencia en nuestro ámbito. Por otro lado, es factible identificar otras posturas que prefieren evitar los gestos estilísticos y buscan una mejora gradual de la tipología por sobre la espectacular ruptura con la tradición para responder a formas reales de vida y desmitificar la idealización de la profesión. En Latinoamérica existen ejemplos de ambas orientaciones, cuyas escalas alcanzan dimensiones notables. La multitendencia globalizada es notable en los ejemplos argentinos difundidos en el mercado bibliográfico. En estos, además del prestigio del profesional y de la imagen de referencia, surgen como condicionantes la seguridad y la necesidad de privacidad. 
Toda mirada hacia la vivienda debe, además, incluir aquella de interés social, cuyo proceso de diseño queda en manos de la autoconstrucción, oficinas gubernamentales o institutos de investigación universitaria dedicados a esta problemática. Debido a las condicionantes económicas, las innovaciones al tipo racionalista compacto son escasas, pero suelen adquirir relevancia las soluciones en el uso de materiales, sistemas tecnológicos locales y componentes prefabricados.

\section{EL PROCESO DE DISEÑO EN LA VIVIENDA LATINOAMERICANA}

El proceso de diseño, recorrido creativo de inventar o descubrir un objeto, se entiende como el desarrollo de fases de un fenómeno que parte de un punto inicial y sigue un camino para llegar a un punto de arribo. El método, por el contrario, es un modo de operar o de conducir un proceso a través de su normalización y codificación, fijándole una dirección conveniente para obtener un resultado óptimo. Se trata de "convertir un proceso en un instrumento para hacer" (Naselli, 2007). Así, es necesario conocer la estructura interna de un proceso para definir un método que lo codifique. Pueden identificarse estos elementos: esquema ordenatriz; posibles estructurantes o fases y orden; elementos estructurales; puntos de iniciación que desencadenan el camino, indican hacia donde evoluciona la transformación del fenómeno y definen el proceso.

En los siguientes ejemplos, algunos ya paradigmáticos, se reflexiona a partir del tipo como "tema-problema" para rescatar lo más significativo de su proceso de diseño, lo cual se entiende como transferible al propio proceso de diseño del estudiante. 


\section{La casa funcionalista}

La casa-estudio de Diego Rivera y Frida Kahlo (figuras 1 y 2), obra de Juan O'Gorman realizada entre 1931 y 1932 en México, intenta romper con los paradigmas estéticos de la arquitectura del país, si bien los principios de Le Corbusier cobran materialidad con elementos puramente mexicanos. Utiliza los cinco puntos para crear una máquina de habitar que responde eficientemente a las necesidades de sus comitentes y a distintos aspectos de las tradiciones locales, tales como el color y la vegetación usada.
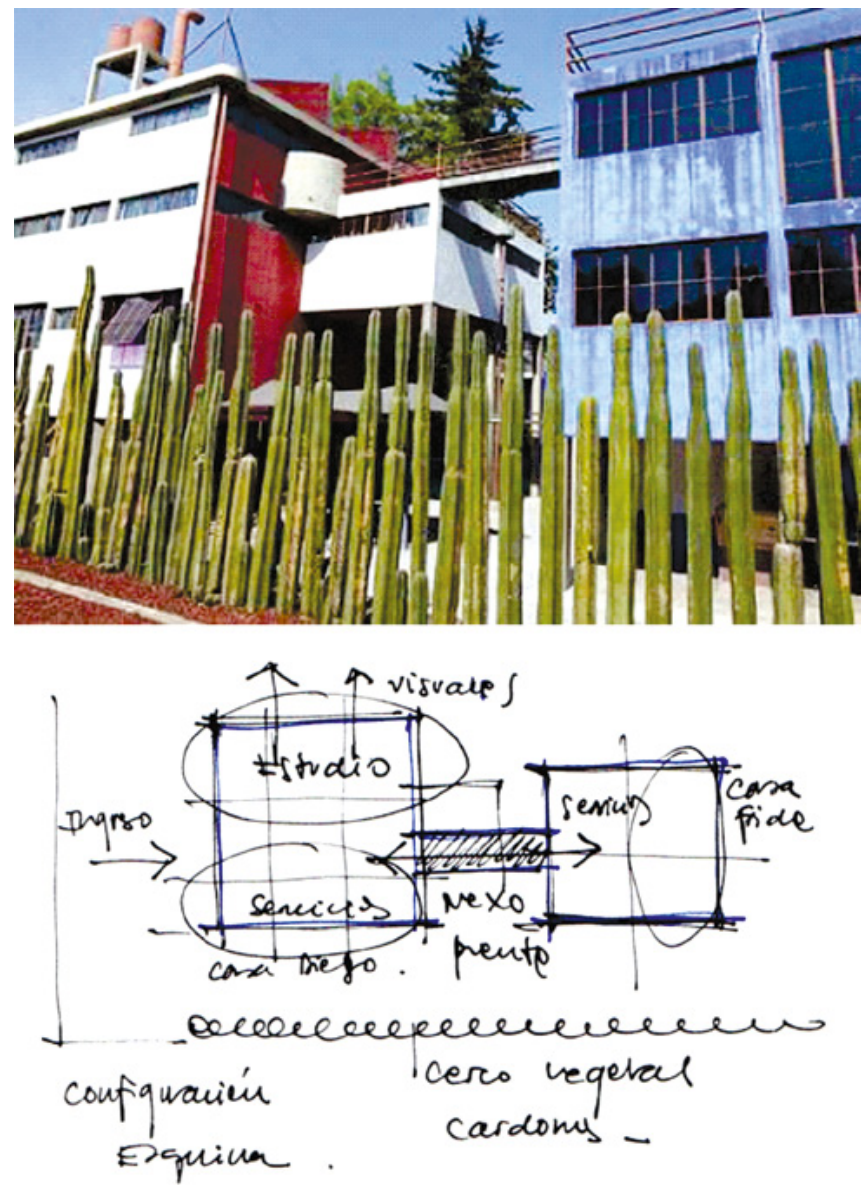

Figura 1. Casa-estudio Rivera-Kahlo, 1931-1932, México.

Figura 2. Esquema del tipo funcional de la casa-estudio Rivera-Kahlo. 
La Casa del Puente (figuras 3 y 4), realizada por Amancio Williams para su padre, músico y compositor, entre 1943 y 1945 en Mar del Plata (Argentina), es una de las propuestas más innovadoras y rigurosas de la arquitectura moderna en este país. Ocupa un predio de dos hectáreas, atravesado por un arroyo sobre el cual se levanta la vivienda. De rigurosidad geométrica, casi abstracta y aérea, es capaz de reducirse a tres elementos básicos: una lámina curva del puente, las líneas horizontales que guían el diseño y el plano de la terraza. Williams estaba convencido del comienzo de una nueva época en que los arquitectos comprometidos con su labor evitarían replicar estilos del pasado para buscar lo mejor en la construcción y lo más puro en belleza.
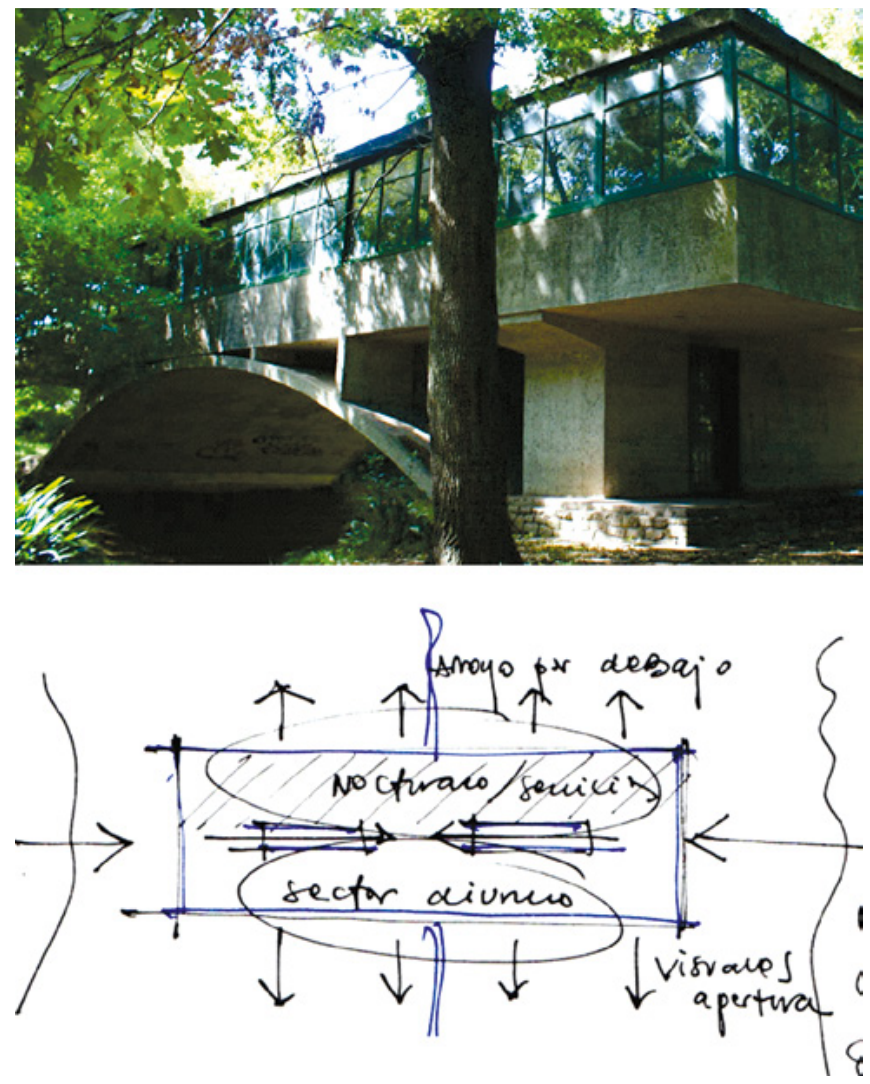

Figura 3. Casa del Puente. Amancio Williams, 1943-1945,

Mar del Plata, Argentina.

Figura 4. Esquema del tipo funcional de la Casa del Puente.

Fuente: autores. 
La vivienda peronista, materializada en Argentina entre 1945 y 1955 en el chalet 'californiano' (figuras 5 y 6), se transforma en uno de los íconos arquitectónicos del período de gobierno y se concibe como "el modelo de vida confortable", al alcance de las familias de obreros y empleados por la Fundación Eva Perón y el Ministerio de Obras Públicas (MOP). De este modo, la vivienda individual en lote propio fue apta para encarnar un horizonte de anhelos emparentado con el ascenso social, cuyo emblema fue "el sueño de la casa propia" y la conquista del respeto burgués. En torno al espacio del hogar "de la familia cristianamente constituida" se condensan representaciones y discursos, mediante un sueño alcanzable con la ayuda del estado, visto por primera vez como garante de los derechos de los trabajadores.

El chalet expresa la confluencia del lenguaje californiano, como revival neocolonial, y la tipología funcional compacta de rasgos modernos. Se produce así una dicotomía entre la expresión exterior que remite a una imagen rural y el modo de habitar, claramente urbano, dado por la racionalización del espacio, lo cual implica profundos cambios en los hábitos de vida cotidianos. Su disposición funcional denota una compacidad como respuesta técnica, económica y racional al problema de la vivienda, agudizado por el gran movimiento interno de población hacia los centros urbanos.

El tratamiento exterior apela a una expresión lingüística pintoresca, apropiable y aprehensible por la población trasplantada a las ciudades, con la intención de ayudar a la adaptación de estas personas a una vida urbana y cosmopolita. El lenguaje "californiano" remite a diversos orígenes que van desde la nostalgia por la vivienda pampeana hasta la influencia cultural norteamericana, a través del cine, de una visión del carácter "colonial hispánico" o "mission style" con la imposición del "american way of life". Dicho lenguaje había sido introducido en el país en las décadas del veinte y del treinta por grupos poblacionales burgueses y fue tomado como símbolo de ascenso social por vastos sectores que pugnaban por incorporarse a la clase media argentina. 
La forma material de la arquitectura residencial peronista se asocia con ideas como la nacionalidad, la identidad y la búsqueda de un sello propio que, mediante la vivienda individual, intenta dar habitación "sana, cómoda y barata" a los argentinos. Asimismo, busca reivindicar el modelo familiar tradicional y el mantenimiento de los roles de la mujer como madre y esposa. La casa es el instrumento que permite perfeccionar las costumbres del buen trabajador justicialista.

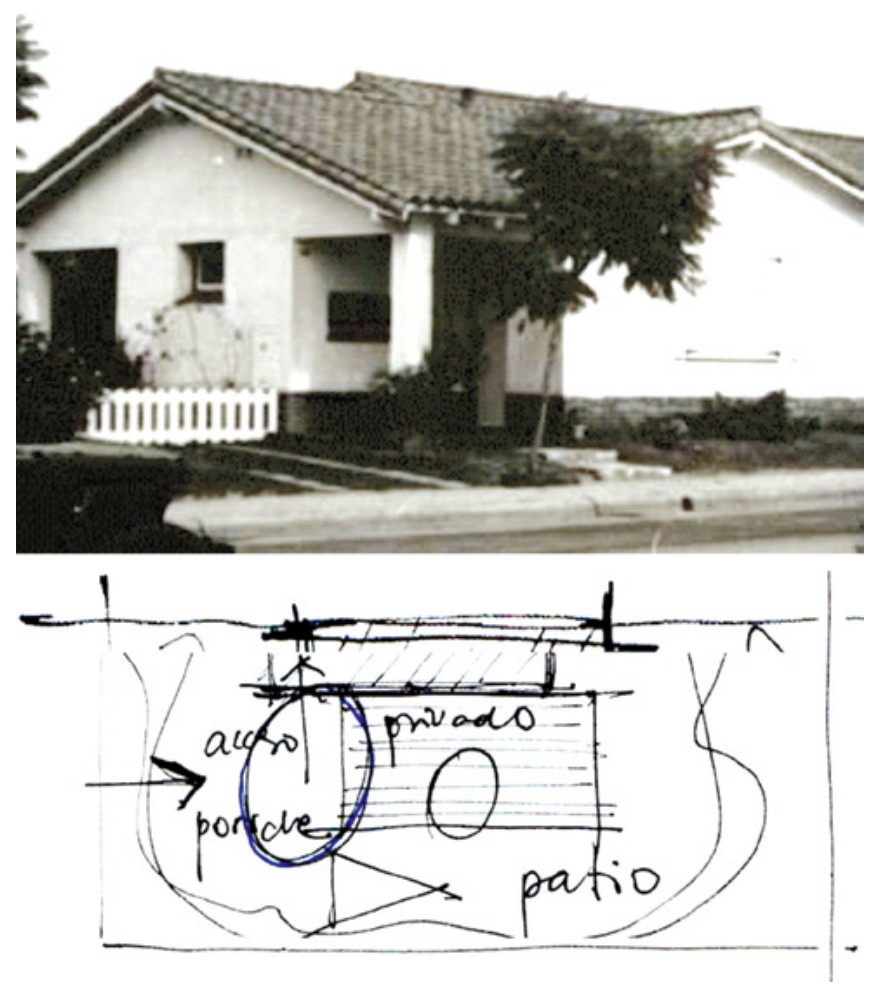

Figura 5. Chalet californiano peronista. Fundación Eva Perón - (MOP), 1945-1955, Argentina

Figura 6. Esquema del tipo funcional del chalet californiano peronista. 


\section{La casa icónica}

Dos condicionantes atrajeron a Luis Barragán a aceptar el encargo de esta vivienda entre medianeras: el enorme árbol Jacarandá cuya presencia debía mantenerse dentro del terreno y la piscina solicitada por el dueño como parte del programa. La casa Gilardi (figuras 7 y 8), construida en 1976 en Tacubaya (México Distrito Federal) se ordena a lo largo sobre un eje que se desliza con un pequeño impacto urbano por fuera e intimista por dentro. El reducido pero potente volumen rosado se defiende de la calle y se vierte al interior para descomponerse hacia el pequeño patio configurado por el cuerpo delantero (servicios, dormitorios) y el trasero (salón-comedor, piscina), ambos unidos por el corredor. El patio así conformado rodea al árbol, el cual era preciso respetar. La disposición en planta, a su vez, descubre poco a poco los espacios a través de filtros de luz y silencio. Un mundo increíble de sensaciones: una entrada sencilla, el efecto de la iluminación cenital. Los colores tienen un rol principal y fueron definidos al pintar grandes cartulinas, colocarlas una tras otra en las paredes, moverlas de lugar y jugar con ellas hasta decidir los tonos cromáticos exactos.

Con pocas referencias del mundo exterior, la casa se afirma en el carácter introspectivo de la vivienda. Los ambientes se asoman al recinto interno a través de grandes superficies acristaladas. La edificación se hizo íntegramente en ladrillo, recubierto en el exterior por un acabado de estuco texturado, típico de la mano de obra mexicana. 
Los interiores, pintados de color, al presentar una textura mucho más lisa permiten a la luz adueñarse del lugar sin producir sombras por la rugosidad. Así, se plasman en gran medida conceptos modernos y elementos compositivos de la cultura mexicana. Igualmente, es indudable la influencia de pintores como Diego Rivera y Frida Kalho. Para el arquitecto autor de esta obra el hombre ha buscado siempre protegerse de la angustia y el temor, ha procurado que los lugares donde habita promuevan la serenidad en su ánimo. De allí la importancia conferida al color.
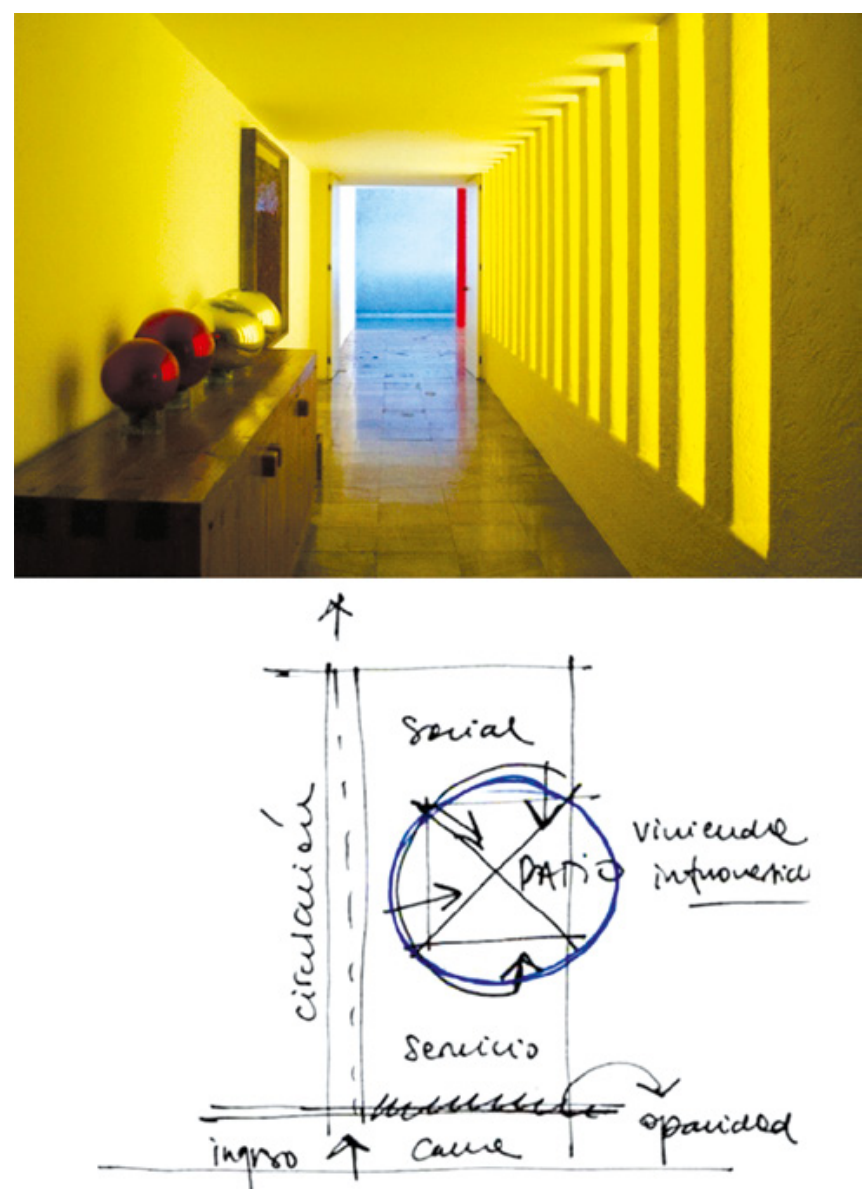

Figura 7. Casa Gilardi. Luis Barragán, 1976,

Tacubaya, México Distrito Federal.

Figura 8. Esquema del tipo funcional de la Casa Gilardi.

Fuente: autores. 


\section{La casa en la ciudad}

Localizada en uno de los barrios jardines de la ciudad de Córdoba (Argentina), la casa Zorzi (figuras 9 y 10), realizada en 1976 por José “Togo" Díaz, se define a partir de la contraposición equilibrada de volúmenes ladrilleros y contundentes que configuran una introvertida esquina abierta hacia el patio. La morfología, resuelta con gran soltura y precisión, se concibe como una prolongación del paisaje circundante y habla de usos, funciones y jerarquías de los locales allí albergados, para expresar así la complejidad del programa. La resolución tipológica evidencia las facetas inevitables y positivas del movimiento moderno al organizar los espacios públicos (sobre el frente más angosto del lote) y los privados (dispuestos longitudinalmente).

Sin embargo, se produce un aporte significativo al modelo a partir de lo simbólico, lo expresivo y estético: el rescate de los patios, los aleros, las galerías convertidas en verdaderos lugares de estar, en busca de las mejores visuales y como forma de prolongar los interiores hacia el exterior. Los recintos se resuelven interconectados por diferentes niveles y visualmente por vanos y ventanas interiores. La forma cilíndrica del hogar, localizado en el espacio principal, refuerza su carácter de centro de la casa. Entre los diversos recursos proyectuales se destacan la transición secuencial del interior al exterior y de un lugar a otro, enfatizada por una gradación de dimensiones y el uso de la luz, como también las circulaciones medidas, las dimensiones generosas que no caen en la ampulosidad y la clara lógica funcional, estética y visual.

Respecto de la materialidad, el ladrillo es el protagonista tanto exterior como interior: el uso de materiales naturales y técnicas constructivas artesanales, presentes en la rugosidad de las soluciones, en los rústicos hogares, en el equipamiento interior de mampostería, en las carpinterías de madera y las tejas, intensifican la expresión formal y cualifican la percepción espacial.

La observación del sitio y la detección de las sugerencias paisajísticas son premisas básicas en esta obra, sin olvidar la escala humana, la variedad de situaciones espaciales, la riqueza de percepciones y el contraste de escala, luz, color y textura que cualifica los espacios. 
En la casa Zorzi puede verse un ejemplo de "modernidad apropiada". Se nutre de todo aquello pertinente a su contexto, conjuga consecuentemente tiempo y espacio, está atenta a su circunstancia social y cultural antes que a efímeras modas. Esta arquitectura ubica al hombre en el centro de la problemática, pero no al hombre abstracto y universal sino al cordobés. Se genera así una arquitectura sincrética que sin desechar los aportes de afuera, realiza una sabia simbiosis con su propia tradición.
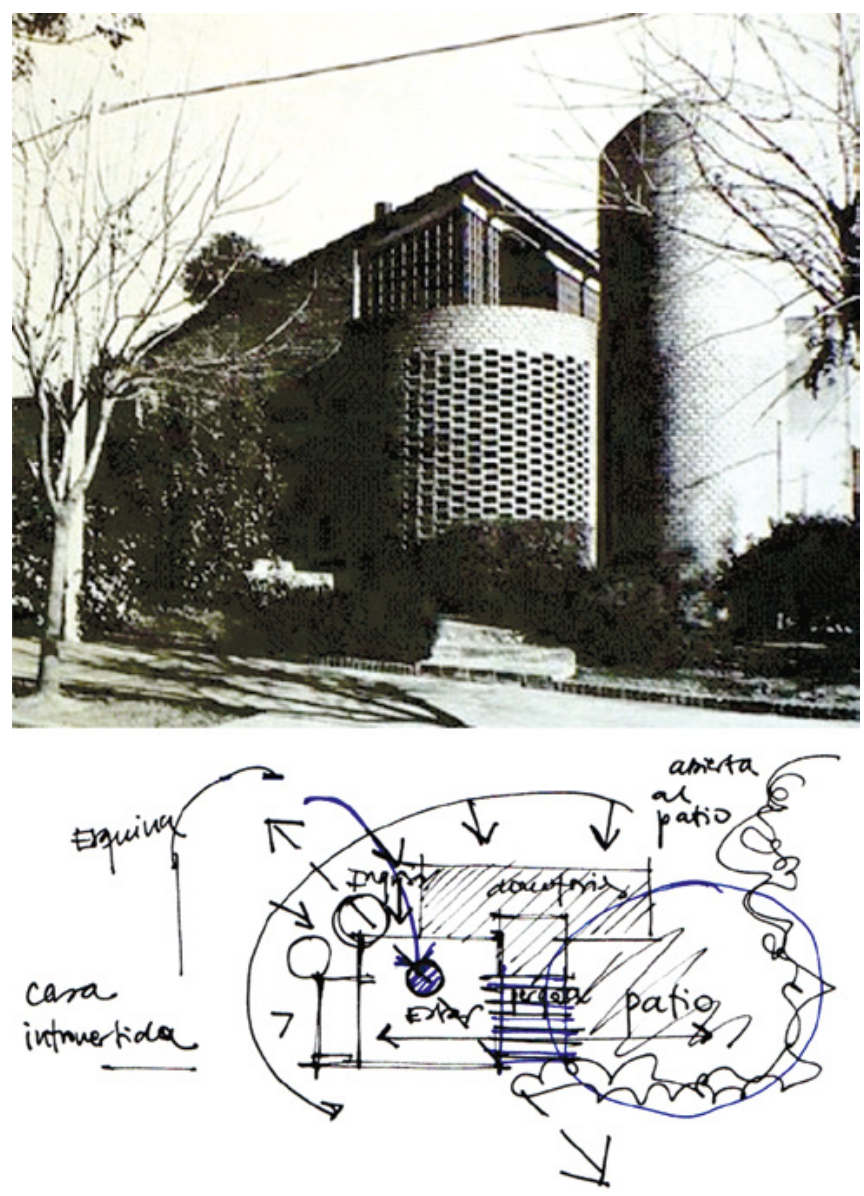

Figura 9. Casa Zorzi. José “Togo” Díaz, 1976, Córdoba, Argentina.

Figura 10. Esquema del tipo funcional de la casa Zorzi. 


\section{La casa práctica}

En la casa Esmeraldina (figuras 11 y 12), construida en 2002 en Asunción (Paraguay) por Solano Benítez y el Gabinete de Arquitectura, se busca un diseño con conceptos geométricos que juega con los ladrillos y la iluminación. Los espacios son el reflejo de pensar y proyectar a modo de ensayo, prueba y error como estrategia proyectual. En estos y en la forma se evidencia una clara influencia de Le Corbusier. La reflexión sobre el problema del lugar se refleja en la preferencia por recursos y materiales de la región. Además, la mirada sobre el paisaje obtenida por Benítez al haber nacido en Asunción se transmite en sus obras, en las que permanente y distintamente relaciona el exterior con su arquitectura y realiza una experimentación plástica del ladrillo.

Si bien el diseño con conceptos geométricos difiere de lo antes visto, es característico del arquitecto el juego con la iluminación y el ladrillo. La elección de este último, utilizado siempre en sus trabajos, no estuvo asociada con propiedades cualitativas, simplemente se eligió por practicidad, pues en Paraguay se produce muy barato y en gran cantidad. El hormigón para los patios interiores es el otro material empleado.

La fachada es la evidencia pura de la búsqueda experimental de Benítez. Así se comprende que los espacios por él proyectados trascienden la condición de lugar y se convierten en reflejo de una manera de pensar y proyectar a modo de ensayo, pues desde un principio se incorporó la prueba y el error como estrategia proyectual. El patio de entrada habla de la transición entre el exterior y el interior. El segundo es parte del núcleo de circulación principal, una zona central que oxigena la vivienda compacta construida entre medianeras. Internamente, los usos protagónicos son 
organizados y se destina un lugar para cada cosa. La influencia de Le Corbusier se lee en la inversión de la organización interna de La Villa Savoye para generar el área libre a nivel de suelo y construir un plano de continuidad entre este y los dormitorios, los cuales quedan contenidos y producen el resguardo del patio.
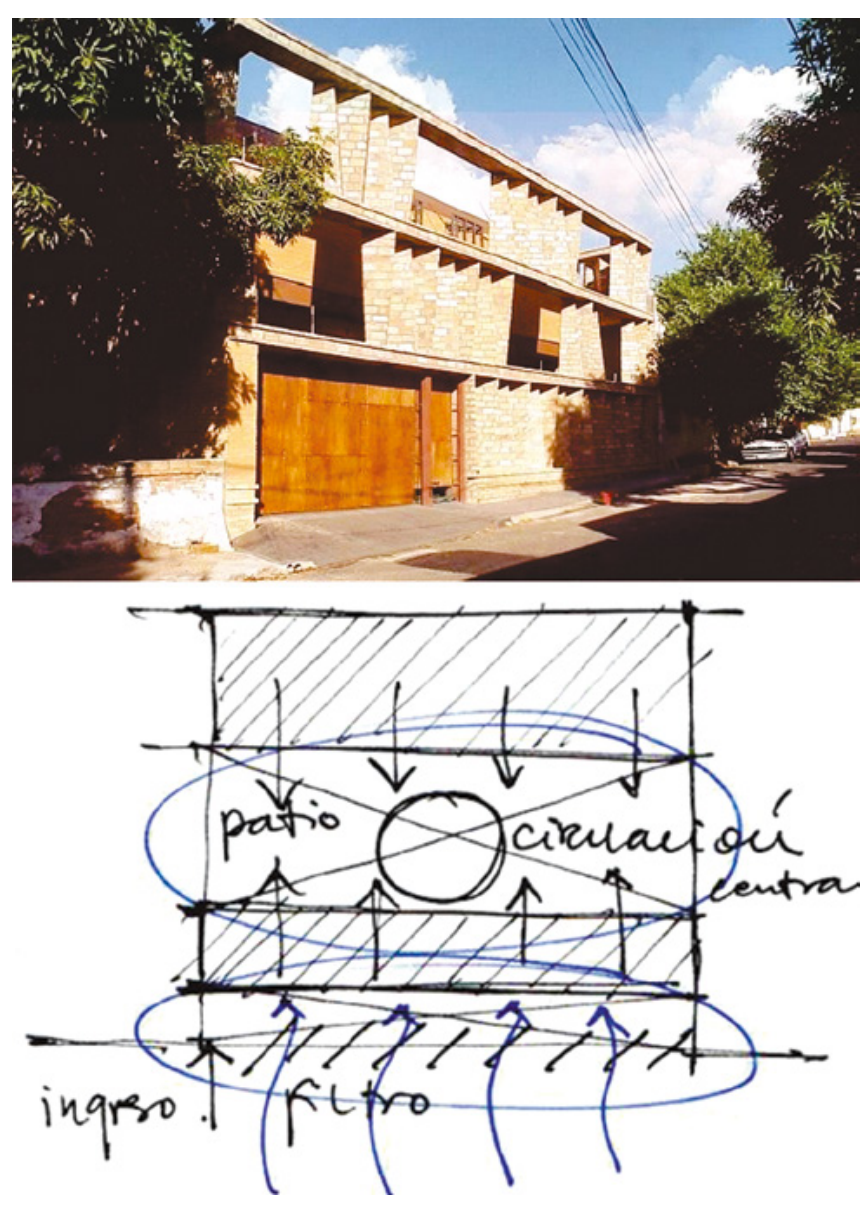

Figura 11. Casa Esmeraldina. Solano Benítez y Gabinete de Arquitectura, 2002, Asunción, Paraguay.

Figura 12. Esquema del tipo funcional de la casa Esmeraldina. 
La casa Codina en Mendoza (Argentina), obra de 2009 autoría de A4estudio (figuras 13 y 14), se recorre teniendo como referencia un patio central de carácter íntimo. Los espacios principales se abren hacia a un gran jardín perimetral de uso más público y condición húmeda, lograda por la orientación norte, para obtener una ganancia térmica directa por asoleamiento. Los espacios secundarios se orientan al este y los servicios se dejan al oeste. La materialidad del proyecto está dominada por un exoesqueleto de hormigón estructural a la vista que alcanza una expresión sutil y severa.

El diseño de las viviendas posmodernas refleja cuan presentes están las temáticas de privacidad y acondicionamiento climático. En esta casa, el proceso implica replantear la integración de la vivienda suburbana en zonas urbanas emergentes de la América latina contemporánea. Se proponen geometrías sensibles a las condiciones del clima, el espacio se entiende como estimulador y se opera desde una conciencia sustentable.
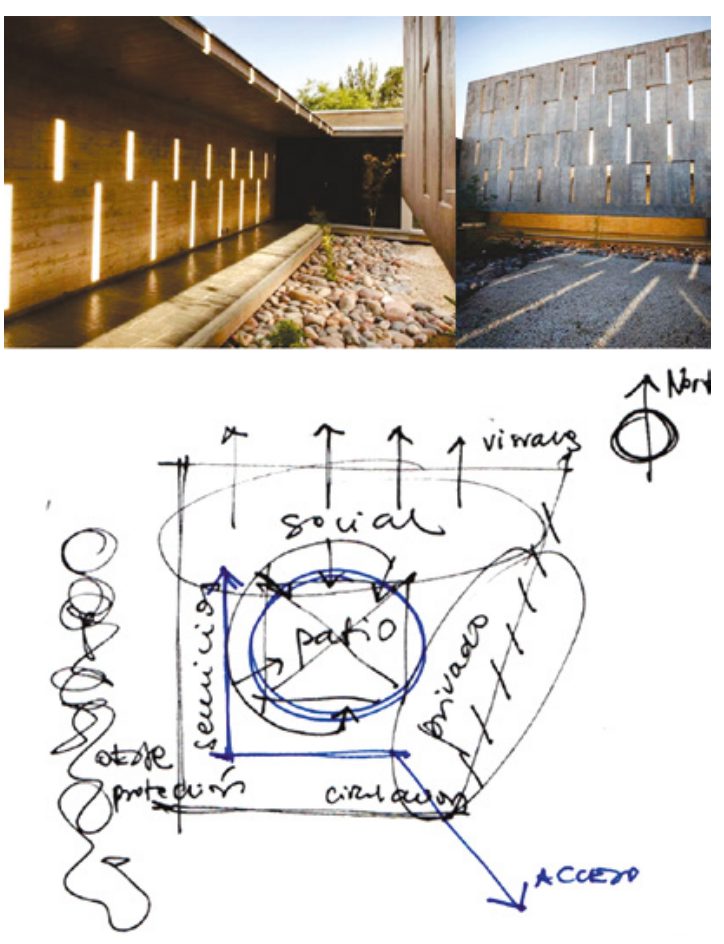

Figura 13. Casa Codina. A4estudio, 2009, Mendoza, Argentina.

Figura 14. Esquema del tipo funcional de la casa Codina. 


\section{CONCLUSIONES}

Toda vivienda busca articular la vida familiar con un orden espacial y estético. Esta tensión entre la casa como obra de arte y marco para la vida diaria está presente en el proceso de diseño desde las primeras décadas del siglo XX hasta nuestros días.

Si la identidad latinoamericana es un proceso dinámico en constante redefinición y construcción, la vivienda también se modifica para responder a necesidades y deseos cambiantes. En distintas épocas históricas, la vivienda en Latinoamérica sirvió de experiencia para las nuevas formas de habitar. Así, la población que migraba de las orillas europeas materializaba nostalgias, posibilidades y cobijo en estrechos terrenos. Luego apareció el sueño de la casa propia abstraída de imaginarios ajenos, para albergar a la porción de clase trabajadora. En la contemporaneidad, coexiste la dualidad de concepciones regionales frente a la innegable realidad globalizada.

La casa es entonces lugar, depósito, ámbito, espacio en la vida colectiva y en la del habitante individual. ¿Cómo saber cuál es la vivienda de cada uno? ¿Cómo saber de qué manera es la vivienda vivida por cada uno? En este marco, siempre abierto al debate, la cátedra apuesta a la práctica gráfica del análisis del tema-problema, busca los aciertos de cada autor al resolver sus desafíos en su espacio y en su tiempo, y mira nuevas obras a partir de reflexiones como la presente para sistematizarlas en la construcción de un observatorio de Arquitectura latinoamericana contemporánea.

\section{REFERENCIAS BIBLIOGRÁFICAS}

Aboy, R. (2005). Viviendas para el pueblo. Espacio urbano y sociabilidad en el barrio Los Perales (1946/1955). Buenos Aires: Fondo de Cultura Económica.

Agacinzki, S. (2008). Volumen: Filosofías y poéticas de la Arquitectura. Editorial: La marca editora. Buenos Aires.

Bachelard, G. (1986). La poética del espacio (2ªed.). México: Fondo de Cultura Económica.

Baldi, J. \& Liston, M. F. (2013). Una domesticidad otra. Reflexiones sobre el habitar contemporáneo. (Lo doméstico del siglo XXI). Trabajo monográfico, Universidad de la República, Montevideo, Uruguay.

Ballent, A. \& Liernur, J. F. (2014). La casa y la multitud: vivienda, política y cultura en la Argentina moderna. Buenos Aires: Fondo de Cultura Económica de Argentina. 
Calmels, D. (2011). Espacio habitado. En la vida cotidiana y la práctica profesional. Rosario, Argentina: Homo Sapiens.

Collado, A. (2008). Historia de la Arquitectura. Problemas y perspectivas de la enseñanza. En L. A. Mendoza (Coord.). La historia en la formación del arquitecto (pp. 35-54). México: Universidad de Colima.

Guerra, V. \& Ravera, C. (2010). Atención, acompañamiento y co-creación en el cuidado del infans y de sus padres. Perspectiva interdisciplinaria. Trabajo presentado en la Jornada del Jardín de Infantes Sol y Luna Mercedes-Soriano.

Levinas, E. (2006). Totalidad e infinito. Ensayo sobre la exterioridad. Salamanca, España: Sígueme.

Montaner, J. M. (2011). Arquitectura y crítica en Latinoamérica. Buenos Aires: Nobuko.

Naselli, C. (2007). Las nociones de proceso y método. Revista 30-60, (1), 28-37.

Patocka, J. (1988). Le monde natural et le mouvement de l'existence humaine. Boston, USA: Kluwe Academia Publishers.

Romero, L. (1997). Latinoamérica: las ciudades y las ideas. Buenos Aires: Siglo Veintiuno.

Rybczynski, W. (2009). La casa: historia de una idea (9ae ed.). San Sebastián: Nerea.

Soulé, M. (1988). La maison et le corps. En D. Anzieu (Ed.). L'enfant et sa maison (pp. 51-61). París: Les Editions ESF.

Taberna, J. (2008). La Casa. Cuaderno Latinoamericano de Arquitectura, (17), 30-60.

Trecco, A. (1979). Tipologías arquitectónicas desde Grecia al siglo XIX. Monografía de grado, Universidad Nacional de Córdoba, Argentina.

Weston, R. (2002). Evolución arquitectónica de la casa en el siglo XX. Barcelona: Art Blume. 